\title{
COMPETITIVIDADE DO BRASIL NO MERCADO INTERNACIONAL DE MADEIRA SERRADA
}

\author{
Sandra Maria Ferreira Couri Petrauski, Gláucio Marcelino Marques², Márcio Lopes da Silva³, \\ Sidney Araujo Cordeiro ${ }^{4}$, Naisy Silva Soares ${ }^{5}$
}

(recebido: 25 de março de 2010; aceito: 28 de outubro de 2011)

RESUMO: Neste estudo, objetivou-se analisar a competitividade da madeira serrada brasileira no mercado internacional, no período de 2000 a 2007. As ferramentas metodológicas utilizadas para confrontar a competitividade do Brasil com a de seus principais concorrentes foram os índices de Posição Relativa no Mercado (PRM) e Vantagem Comparativa Revelada (VCR). Os resultados apontaram para o fato de que, embora o Brasil tenha se mostrado competitivo, faz-se necessária a utilização de estratégias mercadológicas que visem a aumentar a competitividade do país nesse setor.

Palavras-chave: Economia florestal, vantagem competitiva revelada, exportação.

\section{COMPETITIVENESS OF BRAZIL IN THE WOOD INTERNATIONAL MARKET}

ABSTRACT: This study aimed to analyze the competitiveness of Brazilian lumber on the international market in the period 2000 to 2007. The methodological tools used to compare the competitiveness of Brazil with its main competitors were the rates of Relative Position Marketing (PRM) and Revealed Comparative Advantage (VCR). The results point out to the fact that, although Brazil has proved competitive, it is necessary to use marketing strategies aimed at increasing the country's competitiveness in this sector.

Key words: Forest economics, competitiveness, lumber.

\section{INTRODUÇÃO}

A globalização da economia faz com que países comercializem bens e serviços num fluxo que tende a ser cada vez mais ágil. O intercâmbio é resultante das especializações na divisão internacional do trabalho e das vantagens comparativas dos países.

A realização de negócios internacionais envolve características inerentes aos complexos mercados externos e a realidade definida pela maior intensidade competitiva.

O setor florestal brasileiro desempenha um papel de significativa importância e contribuição para o desenvolvimento econômico e social do país. No entanto, sua participação no mercado internacional está aquém do potencial que apresenta, considerada a grandeza da demanda mundial. O setor pode produzir mais e transferir riqueza para outros segmentos da economia. Para ser competitivo, conduzindo esse processo de forma consistente e sustentável, faz-se necessário abrir novos mercados, aumentando as exportações e, simultaneamente, modernizar e assegurar elevado padrão social e ambiental às atividades florestais.

Em termos de estratégia mercadológica, uma das possibilidades do setor produtivo florestal brasileiro ampliar sua participação no mercado internacional é na produção de madeira serrada. Segundo a Associação Brasileira da Indústria da Madeira Processada Mecanicamente ABIMCI (2005), a quantidade de empresas envolvidas na produção de madeira serrada tem diminuído, no entanto, as empresas remanescentes têm ganhado escala e se modernizado.

Nesse contexto, neste estudo, objetivou-se analisar a competitividade da madeira serrada brasileira no mercado internacional, no período de 2000 a 2007. Especificamente, pretendeu-se analisar a evolução e confrontar a competitividade do Brasil e dos principais participantes do mercado internacional nas exportações de madeira serrada, no período considerado.

\footnotetext{
${ }^{1}$ Engenheira Civil, Doutoranda em Ciência Florestal - Departamento de Engenharia Florestal/DEF - Universidade Federal de Viçosa/UFV - 36570-000 Viçosa, MG - petrausk@terra.com.br

${ }^{2}$ Engenheiro Florestal, Doutorando em Ciência Florestal - Departamento de Engenharia Florestal/DEF - Universidade Federal de Viçosa/UFV 36570-000 - Viçosa, MG - gmmarx@gmail.com

${ }^{3}$ Engenheiro Florestal, Professor Dr. em Ciência Florestal - Departamento de Engenharia Florestal/DEF - Universidade Federal de Viçosa/UFV 36570-000 - Viçosa, MG - marlosil@ufv.br

${ }^{4}$ Engenheiro Florestal, Professor Dr. em Ciência Florestal - Departamento de Engenharias/CPCE - Universidade Federal do Piauí/UFPI - 64900-000 Bom Jesus, PI - sidneycordeiro@ufpi.edu.br

${ }^{5}$ Engenheira Florestal, Professora Dra. em Ciência Florestal - Universidade Estadual de Santa Cruz - Rodovia Ilhéus-Itabuna, Km 16, Salobrinho 45650-000 - Ilheus, BA - naisysilva@yahoo.com.br
}

Cerne, Lavras, v. 18, n. 1, p. 99-104, jan./mar. 2012 


\section{MATERIAL E MÉTODOS}

A multiplicidade e diversidade de variáveis que influenciam a competitividade internacional fazem com que esse conceito permita as mais variadas definições associadas a diferentes indicadores. Assim sendo, o conceito de competitividade está associado ao indicador ou ao conjunto de indicadores escolhidos para determinálo (UNIVERSIDADE ESTADUAL DE CAMPINAS UNICAMP, 1993).

Pinheiro et al. (1992), citados por Ângelo (2002) enumeram três linhas conceituais diferentes para avaliar o grau de competitividade de uma economia ou setor: desempenho, macro e eficiência.

O conceito desempenho associa competitividade de um país ao seu desempenho no mercado internacional. Trata-se de um conceito amplo, mas que procura identificar os fatores determinantes da competitividade.

O segundo grupo de indicadores baseia-se no conceito macro, no qual se avalia a competitividade a partir de variáveis que dependem basicamente de decisões de política econômica. Os indicadores mais tradicionais neste grupo são a taxa de câmbio efetiva real e a relação câmbio salário.

O conceito eficiência associa a competitividade de uma economia às suas características estruturais, ou seja, à capacidade do país produzir determinados bens, com níveis de eficiência e qualidade iguais ou superiores aos seus competidores. Nesse grupo, alguns indicadores são os gastos em pesquisa e desenvolvimento tecnológico como proporção do PIB e o número de patentes, por país, por ano.

A teoria sobre a qual se fundamentou o presente estudo foi amparada no conceito desempenho.

Dentre os indicadores de desempenho utilizados ao se analisar a competitividade de um determinado país em setores específicos, uma das principais distinções que podem ser estabelecidas é a relacionada com o caráter absoluto ou relativo dos mesmos. Os indicadores absolutos referem-se, de maneira direta ou indireta, à comparação do desempenho competitivo do país focalizado com o de seus concorrentes no comércio mundial dos produtos respectivos. Já, os indicadores do tipo relativo, em geral denominados indicadores de vantagem comparativa revelada, medem a relação entre o desempenho do setor em questão e o desempenho dos demais setores do mesmo país.

A teoria da vantagem absoluta reflete a capacidade de produção de um bem a partir do menor custo. A teoria da vantagem comparativa, por sua vez, reflete o custo de oportunidade e baseia-se na idéia de que os países devem se especializar na produção dos bens em que são relativamente mais eficientes, ou seja, aqueles em que apresentam vantagens comparativas, adquirindo aqueles em que são relativamente menos eficientes.

O conceito de vantagem comparativa revelada (VCR) foi proposto por Balassa (1965), a partir do reconhecimento da dificuldade de quantificação dos fatores responsáveis pelas vantagens comparativas dos países, incluindo custos relativos e diferenças em fatores não ligados a preços. $\mathrm{O}$ autor sugere que o estudo das vantagens comparativas seja feito a partir da forma em que essas vantagens são reveladas nos padrões de comércio, os quais seriam determinados exclusivamente pelas vantagens comparativas. O indicador pode ser interpretado como sendo a relação para um determinado país, entre a sua participação no mercado de exportações (de um conjunto de países de referência) de um setor específico e a sua participação no mercado total de exportações da indústria manufatureira, sendo expresso por meio da seguinte função matemática:

VCR $=($ Xkpaís $/$ Xtpaís $) /($ Xkmundo $/$ Xtmundo $)$

em que:

$V C R$ = vantagem comparativa revelada,

Xkpaís $=$ valor das exportações do bem $k$ do país no período t;

Xtpaís $=$ valor das exportações totais do país no período t; Xkmundo = valor das exportações do bem $k$ no mundo;

Xtmundo $=$ valor das exportações totais do mundo no período t.

A vantagem comparativa revelada especifica os preços pós-comércio e, é um dos métodos mais utilizados para determinar a vantagem comparativa. É uma medida revelada, tendo em vista que seu cálculo está baseado em dados observados "ex-post" ao comércio, sendo, portanto, inadequada sua utilização para previsões.

A idéia é que o comércio mostra vantagens comparativas reveladas naquele setor analisado. Ou seja, os índices de VCR servem para descrever os padrões de comércio que estão tendo lugar na economia, mas eles não permitem dizer se esses padrões são ótimos ou não. A análise deve ser feita com a interpretação de que índice menor que a unidade indica que o país apresenta uma desvantagem comparativa para o bem considerado, enquanto valor maior que a unidade demonstra que o país possui uma vantagem comparativa revelada no comércio internacional, sendo tanto maior quanto mais alto for o índice.

Cerne, Lavras, v. 18, n. 1, p. 99-104, jan./mar. 2012 
Ainda, no âmbito da construção de indicadores de competitividade, especificamente de desempenho, Silva et al. (2001) apresentam o cálculo da posição relativa de mercado (PRM). O indicador aponta a posição de um país no mercado internacional de um produto, ou seja, focaliza a forma em que a competitividade internacional se manifesta, remetendo à participação do agente estudado no comércio internacional, ao longo dos anos. De modo similar à vantagem comparativa revelada, o índice calculado baseia-se em valores observados “ex-post” ao comércio, devendo ser considerada a mesma observação feita anteriormente relativa ao uso desses tipos de dados.

A posição relativa de mercado é expressa por meio da seguinte função matemática:

$P R M_{i k}^{t}=100 x \frac{X_{i k}^{t}-M_{i k}^{t}}{W_{k}^{n}}$

em que:

$P R M_{i k}^{t}=$ posição relativa do mercado do país $i$ para o bem $k$ no período $t$,

$X_{i k}^{t}-M_{i k}^{t}=$ saldo comercial do país $i$ para o bem $k$ no período $t$;

$W_{k}^{n}=$ total do produto comercializado no mundo, ou seja, valor total das exportações mais as importações mundiais do produto $k$ no período $t$.
No presente trabalho, a análise da competitividade da madeira serrada brasileira baseou-se nos valores calculados dos índices de vantagem comparativa revelada (VCR) e posição relativa no mercado (PRM), tanto para o Brasil quanto para seus principais concorrentes no mercado internacional.

A construção desses indicadores é de grande importância para a formulação de estratégias competitivas e para fundamentar as decisões de caráter privado e políticas governamentais que visem a melhorar a participação da madeira serrada brasileira no cenário internacional.

Os dados utilizados foram obtidos nos sites do Ministério do Desenvolvimento, Indústria e Comércio Exterior (MDIC), Food and Agriculture Organization (FAO), Internacional Trade Center (INTRACEN) e World Trade Organization (WTO). Os valores, expressos em dólares, são anuais e referem-se ao período de 2000 a 2007.

\section{RESULTADOS E DISCUSSÃO}

\subsection{Evolução das exportações de madeira serrada}

A evolução das exportações de madeira serrada do Brasil e seus principais concorrentes, de 2000 a 2007, pode ser observada na Figura 1.

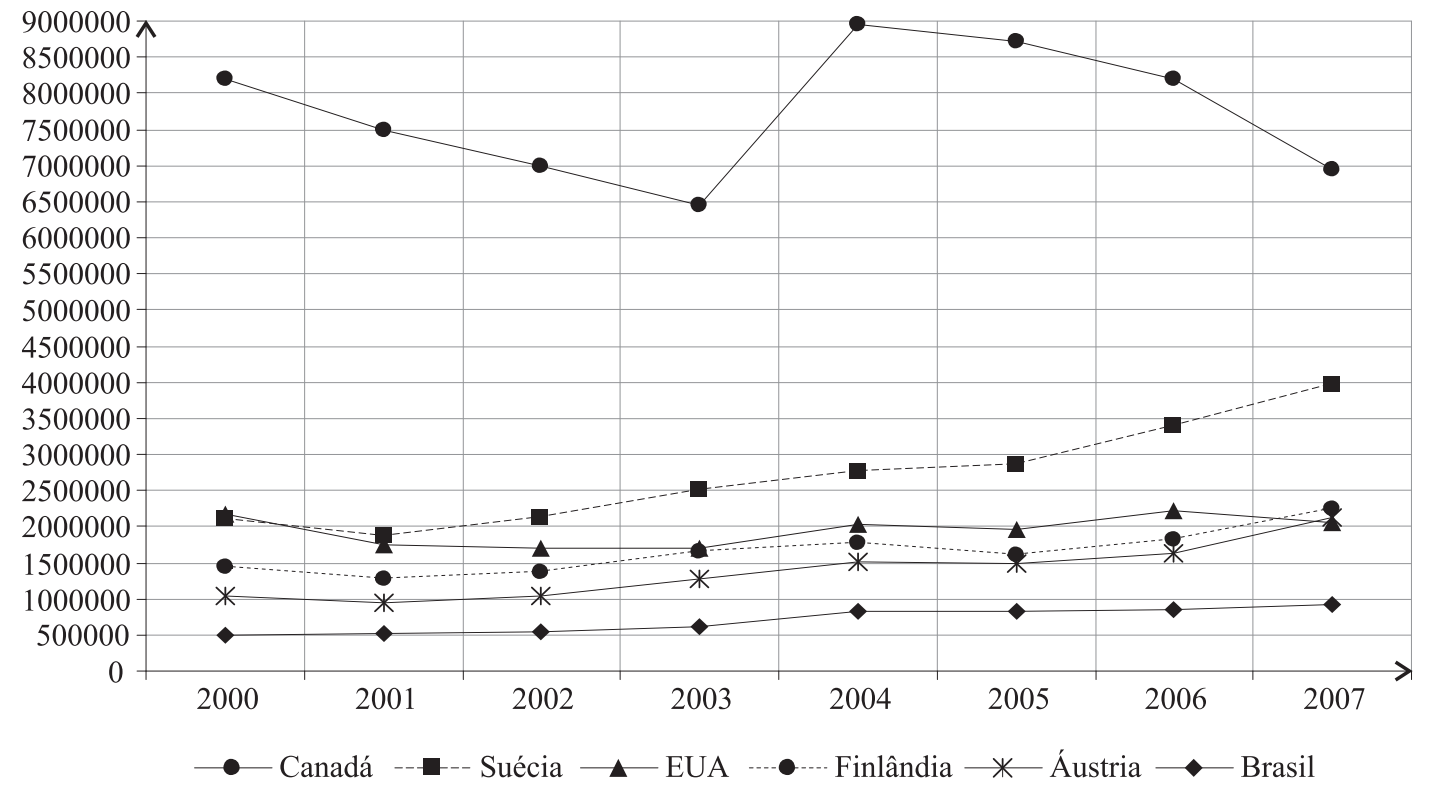

Fonte: Food and Agriculture Organization of the United Nations - FAO (2009).

Figura 1 - Evolução das exportações de madeira serrada do Brasil, Canadá, Suécia, EUA, Finlândia e Áustria, entre 2000 e 2007.

Figure 1 - Exports of sawn timber from Brazil, Canada, Sweden, USA, Finland and Austria, in 2000-2007 period.

Cerne, Lavras, v. 18, n. 1, p. 99-104, jan./mar. 2012 
Pela análise da Figura 1, pode-se notar que o Canadá, apesar da expressiva oscilação, se destacou como o maior exportador de madeira serrada do mundo, entre 2000 e 2007. A Suécia apresentou aumento de suas exportações, no período de 2001 a 2007, passando a ocupar o segundo lugar no mercado internacional de madeira serrada. Comparativamente, os demais países apresentaram uma menor variação de valores no período considerado.

Siqueira (2002) ressalta que a existência de algumas políticas públicas, que favorecem a produção e exportação de produtos florestais, são contribuições fundamentais para o destaque nesse setor de países como o Canadá, a Finlândia, Estados Unidos dentre outros, no comércio internacional.

\subsection{Posição Relativa de Mercado}

Os resultados referentes à PRM do Brasil e de seus principais concorrentes no mercado internacional, no período de 2000 a 2007, são apresentados na Tabela 1.

De acordo com a Tabela 1, ao longo dos anos o Canadá liderou o mercado internacional de exportação de madeira serrada, seguido pela Suécia. Contudo, percebe-se que o índice PRM do Canadá diminuiu aproximadamente $42 \%$ no período total considerado. Possivelmente, isso pode ser atribuído ao fato de que, apesar do país ser o maior exportador mundial de madeira serrada, ocorreu um crescimento de suas importações no período sob análise (FAO, 2009).

Os Estados Unidos tiveram índices PRM negativos, durante todo o período de estudo. Apesar de ser um dos maiores produtores mundiais de madeira serrada, o país também é um dos maiores consumidores do produto, o que explica sua elevada importação do mesmo. Dessa forma, os índices negativos provavelmente se devem ao saldo comercial negativo para madeira serrada do país, ou seja, os valores das importações do produto são superiores aos das exportações.

Os índices PRM da Finlândia e da Áustria apresentaram pequena oscilação e no final do período analisado os países ocupavam a quarta e quinta posição, respectivamente.

Nota-se que o índice PRM da Alemanha foi negativo durante a primeira metade do período analisado, no entanto, em 2007 o país passou a ocupar a sexta posição no Ranking dos países exportadores de madeira serrada. A Indonésia obteve um resultado final inverso, passando da sexta para a nona colocação ao longo dos anos.

A Rússia teve um incremento constante de seu índice, ocupando em 2007 a terceira posição, perdendo apenas para o Canadá e a Suécia. Fato similar pode ser percebido em relação ao Chile, entretanto, em função do baixo valor de seu índice no início do período sob análise, o país ocupou em 2007 a sétima posição, juntamente com o Brasil.

Como pode ser observado, o índice PRM do Brasil indicou que o país ocupou a sétima posição, tanto no início quanto no final do período considerado. Embora tenha ocorrido um aumento das exportações brasileiras, provavelmente o mesmo não tenha sido tão significativo, comparado aos dos seus concorrentes internacionais.

Tabela 1 - Posição Relativa de Mercado (PRM) do Brasil e dos principais exportadores de madeira serrada do mundo.

Table 1 - Relative Market Position (MRP) of Brazil and the world leading lumber exporters.

\begin{tabular}{lccccccccc}
\hline País & 2000 & 2001 & 2002 & 2003 & 2004 & 2005 & 2006 & 2007 \\
\hline Canadá & 15,59 & 15,52 & 14,00 & 11,87 & 13,65 & 13,00 & 11,59 & 8,97 \\
Suécia & 4,08 & 3,90 & 4,30 & 4,74 & 4,22 & 4,25 & 4,86 & 5,18 \\
Finlândia & 2,77 & 2,64 & 2,79 & 3,14 & 2,70 & 2,37 & 2,54 & 2,84 \\
Áustria & 1,58 & 1,59 & 1,71 & 1,96 & 1,88 & 1,75 & 1,67 & 2,15 \\
Rússia & 1,49 & 1,53 & 1,86 & 2,35 & 2,46 & 3,07 & 3,50 & 4,53 \\
Indonésia & 1,18 & 1,68 & 1,32 & 1,25 & 0,97 & 0,90 & 0,82 & 0,75 \\
Brasil & 0,89 & 0,99 & 1,05 & 1,18 & 1,27 & 1,21 & 1,18 & 1,15 \\
Malásia & 0,78 & 1,35 & 1,21 & 1,18 & 0,77 & 1,25 & 1,06 & 0,78 \\
Chile & 0,39 & 0,36 & 0,41 & 0,53 & 0,52 & 1,12 & 1,12 & 1,15 \\
Alemanha & $-0,88$ & $-0,34$ & $-0,60$ & $-0,07$ & 0,37 & 0,86 & 1,12 & 1,73 \\
EUA & $-9,95$ & $-11,22$ & $-10,60$ & $-8,61$ & $-11,66$ & $-11,19$ & $-9,27$ & $-6,21$ \\
\hline
\end{tabular}

Fonte: Resultados da Pesquisa.

Cerne, Lavras, v. 18, n. 1, p. 99-104, jan./mar. 2012 
Noce et al. (2003) estudaram a competitividade dos principais exportadores de madeira serrada, por meio da decomposição das variações nas exportações de madeira no período de 1997 a 1999. Foram analisados Brasil, Canadá, Estados Unidos, Finlândia e Suécia pelo modelo Constant Market Share. A aplicação do modelo possibilitou constatar que o aumento das exportações brasileiras no período deveu-se a fatores endógenos, ao contrário do que foi observado em relação às outras nações. Concluíram que a competitividade brasileira apoiou-se principalmente em fatores internos, como custo, sistema produtivo, qualidade do produto e taxa de câmbio.

Segundo Donnelly (2001), apesar das exportações de madeira brasileira ainda estarem em desenvolvimento, a situação do mercado de exportação para o Brasil é positiva e com grande potencial. De acordo com o autor, o Brasil precisa desenvolver uma base industrial forte que seja capaz de produzir uma larga escala de produtos de madeira e comercializá-los tanto no mercado interno quanto externo.

\subsection{Vantagem Comparativa Revelada}

Na Tabela 2, apontam-se os valores relativos à VCR do Brasil e de seus principais concorrentes no mercado internacional, no período de 2000 a 2007.

Percebe-se que, com exceção dos Estados Unidos e da Alemanha, todos os países analisados possuem vantagem comparativa no mercado internacional de madeira serrada.

Conforme informações da Tabela 2, a Finlândia apresentou os maiores valores para o índice VCR. Tais resultados indicam que, comparativamente, a parcela de contribuição do setor de madeira serrada nas exportações totais do país é superior a dos demais países analisados.

Para a maioria dos países, no período considerado, o índice de VCR apresentou pequenas oscilações, com exceção do Canadá, da Suécia, do Chile e da Rússia. A Suécia, a partir de 2006, superou o Canadá apresentando o segundo maior valor para o índice. O Chile aumentou sua exportação de madeira serrada no período sob análise, o que refletiu no aumento de seu índice VCR, entretanto, o país manteve-se com o quinto maior valor ao longo dos anos. Provavelmente, isso foi decorrente do aumento das exportações de madeira serrada dos outros países como, por exemplo, da Rússia.

De acordo com a Tabela 2, o Brasil não conseguiu aumentar seu índice de VCR no período sob análise, mantendo-se com o sétimo maior valor.

Enquanto estratégias brasileiras visando ao aumento das exportações de madeira serrada e, consequentemente, a competitividade do país nesse setor, a ABIMCI (2008) apresenta, dentre outras sugestões: a melhoria da eficiência (floresta-indústria-mercado); o aumento dos níveis de produtividade; ganho de escala e diversificação de mercados. No referente a esse último aspecto, menciona a importância do fortalecimento de contatos comerciais com a América do Sul, Europa e China. A ascensão do mercado chinês tem se mostrado extraordinária e o crescimento da demanda por madeira serrada desse país aumentou de 6 para 22 milhões de $\mathrm{m}^{3}$ no período analisado de 2000 a 2007.

Tabela 2 - Vantagem Comparativa Revelada (VCR) dos 11 maiores exportadores de madeira serrada do mundo.

Table 2 - Revealed Comparative Advantage (VCR) of the 11 largest world lumber exporters.

\begin{tabular}{|c|c|c|c|c|c|c|c|c|}
\hline País & 2000 & 2001 & 2002 & 2003 & 2004 & 2005 & 2006 & 2007 \\
\hline Finlândia & 8,53 & 9,29 & 8,62 & 9,61 & 8,75 & 8,25 & 8,57 & 9,66 \\
\hline Canadá & 8,14 & 8,71 & 7,80 & 7,24 & 8,53 & 8,05 & 7,67 & 6,39 \\
\hline Suécia & 6,65 & 7,68 & 7,18 & 7,47 & 6,76 & 7,28 & 8,40 & 9,06 \\
\hline Áustria & 4,23 & 4,36 & 4,03 & 4,40 & 4,15 & 4,20 & 4,38 & 5,23 \\
\hline Chile & 2,71 & 2,81 & 3,35 & 4,18 & 3,27 & 6,12 & 4,88 & 4,87 \\
\hline Indonésia & 2,62 & 3,08 & 3,25 & 3,37 & 2,80 & 2,50 & 2,29 & 2,16 \\
\hline Brasil & 2,44 & 2,33 & 2,56 & 2,59 & 2,61 & 2,30 & 2,23 & 2,22 \\
\hline Rússia & 1,90 & 2,04 & 2,29 & 2,69 & 2,52 & 2,67 & 2,79 & 3,56 \\
\hline Malásia & 1,20 & 1,36 & 1,97 & 2,02 & 1,59 & 2,20 & 2,01 & 1,66 \\
\hline EUA & 0,76 & 0,83 & 0,69 & 0,71 & 0,75 & 0,72 & 0,77 & 0,68 \\
\hline Alemanha & 0,42 & 0,41 & 0,45 & 0,45 & 0,50 & 0,62 & 0,74 & 0,82 \\
\hline
\end{tabular}

Fonte: Resultados da Pesquisa.

Cerne, Lavras, v. 18, n. 1, p. 99-104, jan./mar. 2012 
AABIMCI ressalta-se também que o relacionamento do Brasil com os países árabes no mercado da madeira serrada está se fortalecendo, em razão do crescimento da construção civil nesses países e às crises econômicas ocorridas nos últimos anos na Europa e Estados Unidos.

Utilizando-se dessas e de outras estratégias mercadológicas, a madeira serrada brasileira pode vir a ganhar competitividade para atingir novos mercados, e, desde que políticas econômicas adequadas sejam utilizadas pelo setor público, poderia ser viabilizada a expansão de mercados, permitindo aumentar os rendimentos desse setor no Brasil.

\section{CONCLUSÕES}

Considerando as condições de desenvolvimento deste estudo, as seguintes conclusões principais parecem relevantes:

- a hegemonia canadense no mercado internacional de madeira serrada é notória, ocorrendo grande diferença entre os valores de exportações do país em relação aos demais exportadores internacionais do produto, no período de 2000 a 2007 ;

- embora tenha ocupado a quarta posição no Ranking dos países exportadores de madeira serrada, a Finlândia mostrou-se como o país que possuiu a maior vantagem comparativa revelada no comércio internacional do produto, durante todo o período de análise;

- o Brasil, embora competitivo, ocupou a sétima posição entre os principais exportadores de madeira serrada do mundo;

- a utilização de estratégias mercadológicas de ampliação da participação brasileira no mercado internacional de exportação de madeira serrada poderia aumentar a competitividade do país nesse setor.

Sugere-se para trabalhos futuros uma análise da competitividade do Brasil no mercado internacional de madeira serrada utilizando uma ferramenta metodológica que permita fazer projeções para o futuro sobre a competitividade do país no referido mercado.

\section{REFERÊNCIAS}

ÂNGELO, H. Implicações da certificação florestal na competitividade da madeira tropical brasileira no mercado internacional. Brasília: Ministério do Meio Ambiente, 2002. 38 p.

\section{ASSOCIAÇÃO BRASILEIRA DA INDÚSTRIA DA} MADEIRA PROCESSADA MECANICAMENTE.

Estudo setorial 2004: indústria de madeira processada mecanicamente. Brasília, 2005. Disponível em: <http://www. abimci.com.br>. Acesso em: 28 out. 2009.

\section{ASSOCIAÇÃO BRASILEIRA DA INDÚSTRIA DA} MADEIRA PROCESSADA MECANICAMENTE.

Estudo setorial 2008: indústria de madeira processada mecanicamente. Brasília, 2005. Disponível em: <http://www. abimci.com.br>. Acesso em: 28 out. 2009.

\section{BALASSA, B. El desarrollo econômico y la integracion.} México: Centro de Estudios Monetarios Latinoamericanos, 1965. 151 p.

DONNELLY, R. H. Mercado: alternativas de mercado externo para produtos de madeira no Brasil. Revista da Madeira, Curitiba, v. 11, n. 60, p. 10-18, 2001.

FOOD AND AGRICULTURE ORGANIZATION OF THE UNITED NATIONS. Disponível em: <http://www.fao.org>. Acesso em: 28 out. 2009.

NOCE, R. et al. Desempenho do Brasil nas exportações de madeira serrada. Revista Árvore, Viçosa, v. 27, n. 5, p. 695700, set./out. 2003.

SILVA, V. da; ANEFALOS, L. C.; REIS FILHO, J. C. G. de. Indicadores de competitividade internacional dos produtos agrícolas e agroindustriais brasileiros, 1986-1998. São Paulo: IEA-SP, 2001. Disponível em: <htttp://www.iea.sp.gov. br/out/vertexto.php?com=412>. Acesso em: 29 out. 2009.

SIQUEIRA, J. P. Proposta para a melhoria da comercialização de produtos florestais. Brasília: Ministério do Meio Ambiente, 2002. 88 p.

UNIVERSIDADE ESTADUAL DE CAMPINAS. Estudo da competitividade da indústria brasileira: sistema de indicadores da competitividade. Campinas, 1993. 202 p.

Cerne, Lavras, v. 18, n. 1, p. 99-104, jan./mar. 2012 